DR. MARIA JOSÉ CABAÑERO-MARTÍNEZ (Orcid ID : 0000-0002-8333-2988)

DR. JUAN DIEGO RAMOS-PICHARDO (Orcid ID : 0000-0002-6207-8490)

DR. SOFÍA GARCÍA-SANJUAN (Orcid ID : 0000-0001-7985-7864)

Article type : Original Article

\title{
Availability and perceived usefulness of guidelines and protocols for subcutaneous hydration in palliative care settings.
}

Short title: Guidelines for subcutaneous hydration

\section{Authors}

María José Cabañero-Martínez, PhD.

Department of Nursing. University of Alicante. Spain

Juan Diego Ramos-Pichardo, $\mathrm{PhD}$.

Department of Nursing. University of Huelva. Spain

María Luisa Velasco-Álvarez, PhD.

Department of Nursing. University of Alicante. Spain

Sofía García-Sanjuan, $\mathrm{PhD}$.

Department of Nursing. University of Alicante. Spain

Manuel Lillo-Crespo, $\mathrm{PhD}$.

Department of Nursing. University of Alicante. Spain

Julio Cabrero-García, PhD.

Department of Nursing. University of Alicante. Spain

This article has been accepted for publication and undergone full peer review but has not been through the copyediting, typesetting, pagination and proofreading process, which may lead to differences between this version and the Version of Record. Please cite this article as doi: 10.1111/jocn.15036

This article is protected by copyright. All rights reserved. 
Corresponding Author: Juan Diego Ramos-Pichardo, Department of Nursing. Nursing Faculty. University of Huelva, Campus El Carmen, University of Huelva, Avda. Tres de Marzo, s/n, 21071 Huelva, Spain (juan.ramos@denf.uhu.es)

Telephone number: 34959218358

\section{Acknowledgments}

We would like to thank all health professionals from each of the participating institutions for their cooperation, in particular those who participated in the interviews.

\section{Funding}

This study has been funded by a grant from the Institute of Health Carlos III (PI10/00847) of the Ministry of Economy and Competitiveness (Spain) and the European Regional Development Fund (FEDER).

\section{Compliance with ethical standards}

This study received approval from the Ethics Committee of the University of Alicante (ref. no. UA-2014-07-31) and informed consent was procured from all participants. Authors have full control of all primary data and agree to allow the journal to review their data if requested.

\section{Conflict of interest}

No conflict of interest has been declared by the authors.

This article is protected by copyright. All rights reserved. 


\section{Abstract}

Aims and objectives: To evaluate the availability of, adherence to, and perceived usefulness of guidelines and protocols for managing hydration and subcutaneous hydration in palliative care settings.

Background: Hydration at the end of life and the use of a subcutaneous route to hydrate generate some controversy among health professionals for different reasons. Having guidelines and protocols to assist in decision making and to follow a standard procedure may be relevant in clinical practice.

Design: Cross-sectional telephone survey, with closed-ended and open-ended questions designed specifically for this study.

Methods: Data were obtained from 327 professionals, each from a different palliative care service. Mean, standard deviation, minimum and maximum were calculated for continuous variables; frequency distributions were obtained for categorical variables. A qualitative content analysis was performed on the open-ended questions. The article adheres to the STROBE guidelines for reporting observational studies.

Results: Only $24.8 \%$ of the participants had guidelines available to assist in making decisions regarding hydration, and $55.6 \%$ claimed to follow them "always or almost always". Of the participants, $38.8 \%$ had subcutaneous hydration protocols available, while $78.7 \%$ stated that they "always or almost always" followed these protocols. The remaining participants considered the protocols useful tools despite not having them available.

Conclusions: Only 25\% of the participants' services had guidelines for hydration, and less than $40 \%$ had protocols for subcutaneous hydration. However, adherence was high, especially in cases where protocols existed. Among the participants who did not have guidelines and protocols, attitudes were mostly favourable, but mainly as a reference and support for an individualized clinical practice.

This article is protected by copyright. All rights reserved. 
Relevance to Clinical Practice: Guidelines and protocols on hydration in palliative care may be more useful as a solid reference and support for individualized practice than as instruments for standardizing care. From this perspective, their development and availability in palliative care services are recommended.

Keywords: Hydration Status; Hypodermoclysis; Palliative Care; End of Life; Withholding Treatment; Guideline.

\section{What does this paper contribute to the wider global clinical community?}

- Only one-quarter of palliative care services had guidelines for hydration, and less than half had protocols for subcutaneous hydration.

- The adherence to these tools was high, especially in the case of protocols.

- In services that did not have these tools, the attitudes of professionals were mostly favourable to their existence but mainly as a reference and support for individualized clinical practice.

\section{Introduction}

Variations in clinical practice are common and are not necessarily unfavourable (Nouhi, Hadian, \& Olyaeemanesh, 2018). Factors such as patient clinical characteristics and preferences or available resources (e.g., technological) may make some variations in clinical practice necessary (Cheung \& Gray, 2013; Malhotra, Chan, Zhou, Dalager, \& Finkelstein, 2015).

However, it has been documented that there are patients who receive interventions that do not fully meet their needs (Van Brabandt et al., 2006). These variations, called unwarranted 
variations, can seriously affect the health status of patients (Gupta \& Cook, 2013; Pellet, Erten, \& James, 2016). This can be even more serious in those interventions where the available evidence is inconclusive, as professionals may have doubts when making decisions. Artificial hydration in palliative care remains a controversial issue on which there is no consensus. Some authors claim that it reduces delirium induced by dehydration. However, others have described end-of-life situations in which symptoms such as increased respiratory secretions or fluid retention may worsen, causing more harm than good for the patient (Bear, Bukowy, \& Patel, 2017; Torres-Vigil et al., 2012).

In situations in which the available evidence is inconclusive, as in cases of uncertainty or ethical doubts, the guidelines not only are a solid way to standardize clinical practice but also can be an important basis for individualized attention and decision-making if they are applied according to the clinical judgement of the professionals and the wishes of the patients (Papanikitas \& Lunan, 2018).

\section{Background}

The development of clinical guidelines, decision-making algorithms and healthcare protocols are clear examples of actions aimed at controlling unwarranted variability in decision-making processes (Mercuri \& Gafni, 2011). While these terms refer to different decision-making tools, they are often used interchangeably (Considine \& Hood, 2000; Hewitt-Taylor, 2004). The term "guideline" refers to "systematically developed statements to assist decisions made by practitioners and patients regarding appropriate healthcare for specific clinical circumstances" (Audet, Greenfield, \& Field, 1990; Institute of Medicine (US) Committee to Advise the Public Health Service on Clinical Practice Guidelines, Field, \& Lohr, 1990; Keffer, 2001). Algorithms, derived from mathematics, have been described as "a systematic set of rules for solving a particular problem with ambiguous alternatives and having a clear 
stopping point" (Keffer, 2001). In many cases, guidelines incorporate clinical algorithms that synthesize various alternatives for action. Finally, protocols can be defined as "rigid statements allowing little or no flexibility or variation. A protocol sets out a precise sequence of activities to be adhered to in the management of a specific clinical condition. There is a logical sequence and precision of listed activities" (Broughton, 2001).

The main problem inherent in such strategies, as a result of their complexity, lies in their implementation and adherence by professionals in a clinical context (Schellart, Zwerver, Anema, \& van der Beek, 2013). This has made the introduction of and adherence to such strategies the focus of research from a range of medical fields over recent decades (Prior, Guerin, \& Grimmer-Somers, 2008; Tomasone, Chaudhary, \& Brouwers, 2015). Several studies suggest that non-adherence to guidelines is widespread among health professionals (Corallo et al., 2014; Gouvêa, Novaes, Pereira, \& Iglesias, 2015). Nonetheless, health professionals believe that the variability in clinical practice is not worrisome and that such variability is justified by clinical differences between patients (Arts, Voncken, Medlock, Abu-Hanna, \& van Weert, 2016; Cook et al., 2018).

In palliative patients, and especially end-of-life situations, the prescription and/or withdrawal of hydration has raised great concern among professionals and the wider public due to its clinical, ethical and legal significance, constituting one of the main dilemmas in decisionmaking processes shared among patients, relatives and healthcare professionals (Gent, Fradsham, Whyte, \& Mayland, 2015; Higgins, van der Riet, Sneesby, \& Good, 2014; Río et al., 2012). The most recent reviews show that there is limited evidence to support the use of artificial hydration in improving sedation and myoclonus or reducing dehydration (Good, Richard, Syrmis, Jenkins-Marsh, \& Stephens, 2014), and artificial hydration may exacerbate symptoms associated with fluid retention, such as oedema, ascites, bronchial secretions and dyspnoea (Gent et al., 2015; Good et al., 2014; Nakajima, Satake, \& Nakaho, 2014). 
Moreover, there is no evidence that artificial hydration improves thirst, delirium or fatigue (Gent et al., 2015; Good et al., 2014). Consequently, the practice of artificial hydration in these situations remains an unfounded practice supported by weak evidence (Forbat, Kunicki, Chapman, \& Lovell, 2017). Institutions such as the National Institute for Health and Care Excellence (NICE), the European Society for Clinical Nutrition and Metabolism (ESPEN) and other scientific associations have developed tools (guidelines, monographs, clinical pathways) that facilitate decision-making processes and approaches to hydration in end-oflife patients (Druml et al., 2016; National Institute for Health and Care Excellence, 2015). Nevertheless, no studies currently exist that analyse the availability of such tools (have guidelines or protocols ready to use in their services or hospitals) and the adherence by healthcare professionals to them.

As such, the present study aims to evaluate the availability of, adherence to, and perceived usefulness of guidelines and protocols for managing hydration, as well as that of subcutaneous hydration protocols, in palliative care settings.

\section{Methods}

\subsection{Design}

A cross-sectional study was conducted using a telephone survey with closed-ended and openended questions designed specifically for this study.

\subsection{Participants}

The professionals who participated in the study came from the services listed by the Spanish Society of Palliative Care (Sociedad Española de Cuidados Paliativos) that care for patients in end-of-life situations. These data were cross-matched with information available from regional coordination centres and the Spanish Society of Home Hospitalization (Sociedad 
Española de Hospitalización a Domicilio). A total of 461 services were identified, of which a final 353 were eligible. The rest were excluded because they either did not care for palliative patients but only provided psychological support or were unable to be contacted.

\subsection{Procedure}

Coordinators of each eligible service were contacted via telephone with the aim of verifying the resources available at their centre, explaining the nature of the study and the characteristics of the questionnaire and requesting their collaboration and consent. Among those who agreed to participate (327 of the 353 eligible services, $92.6 \%$ response rate), a professional was chosen, preferably the coordinator, as long as that individual directly treated patients. In the event that this position did not exist or did not care for patients, the team was asked to choose one of its members to be interviewed. The professional interviewed was asked to respond on behalf of the entire team of that service.

Three researchers (MJCM, JDRP, MLVA) with experience in conducting interviews carried out interviews following a standardized procedure for contacting participants and conducting the telephone interview. All of them were trained in the protocol of contact and administration and followed the same script of presentation, information, informed consent and development of the interview to ensure consistency among them.

\subsection{Data collection}

Data collection was carried out from May 2013 to June 2014 via a questionnaire designed specifically for this study. The contents of this questionnaire were based on information extracted from a previous study conducted through four focus groups that analysed both the decision to hydrate and the subcutaneous hydration procedure applied (Cabañero-Martínez et al., 2016). The questionnaire included both closed-ended and open-ended questions. Through

This article is protected by copyright. All rights reserved. 
closed-ended questions, all participants were asked about the availability and readiness to use in their services or hospitals algorithms or clinical guidelines on patient hydration, as well as the existence of specific protocols for the administration of subcutaneous hydration. Additionally, with closed-ended questions, participants who claimed to have some of these tools were consulted about the authors of the tool, its publication date and the degree of adherence by the team to the recommendations. Finally, through an open-ended question, those who did not have guidelines, algorithms or protocols available were asked to indicate whether they considered them useful and to describe the reasons for their response.

The comprehensibility of the items in the questionnaire was evaluated with the collaboration of five palliative service coordinators from the Autonomous Community of Valencia to assess comprehensibility and the time required to undertake the questionnaire. Subsequently, to validate and standardize the procedure for presenting and administering the questionnaire, a pilot study was carried out with a subsample of 50 palliative services professionals, randomly selected from the total of services through a table of random numbers. The standardized protocol for the presentation and administration of the study did not show difficulties or require changes. Data from the pilot study subsample were therefore included in the final analysis sample.

\subsection{Data analysis}

A descriptive analysis was conducted of the questionnaire's categorical and continuous variables. The mean, standard deviation, minimum and maximum values and $95 \%$ confidence interval were calculated for continuous variables; frequency and percentage distributions, as well as a $95 \%$ confidence interval, were obtained for categorical variables.

A qualitative content analysis (Guba \& Lincoln Y.S., 1994) was performed on the openended question regarding the reasons healthcare professionals considered the use of 
guidelines, algorithms and protocols useful. The responses were analysed by three researchers, two of whom did not participate in the prior data collection, while the other did. All of them were experienced in this type of methodology. All three researchers analysed the responses independently and agreed on a system for codifying the information through consensus meetings. Subsequently, and again consensually, by using content analysis, the textual material from the open-ended questions was interpreted, coded and finally grouped into categories from which themes merged, as explained later in the results.

Throughout the research process, we adhered to the Strengthening the Reporting of Observational Studies in Epidemiology (STROBE) Statement guidelines (Vandenbroucke et al., 2007) (Supplementary File 1).

\subsection{Compliance with ethical standards}

This study received approval from the Ethics Committee of the University of Alicante (ref. no. UA-2014-07-31), and informed consent was procured from all participants.

\section{Results}

Of the 327 units that agreed to participate, Table 1 shows their characteristics: $32.7 \%$ were from Catalonia, $44.7 \%$ were home-based healthcare teams, $32.7 \%$ were hospital-based and $22.6 \%$ cared for patients both at home and in hospitals. Moreover, 90.5\% cared for patients requiring palliative care due to oncological and non-oncological processes. Most of the interviewees were medical coordinators $(87.8 \%(n=287))$.

\subsection{Guidelines for hydration (Table 2)}

Of the participants, $24.8 \%(\mathrm{n}=81)$ claimed to have guidelines or algorithms available at their services or hospitals for making decisions on hydration. Likewise, regarding the creation of 
these tools, most $(75.3 \%$; $=61)$ participants indicated that they had been compiled by a committee of various professionals. In analysing the composition of these committees, it was found that most were made up of medical doctors and nurses $(63.9 \% ; n=39)$. With regard to the possible obsolescence of the tools in use, the dates over which these guidelines and/or algorithms were created covered a period of 23 years (1991-2014), with $43.2 \% \quad(n=35)$ compiled during the previous decade and $32.1 \%(\mathrm{n}=26)$ compiled during the current decade. Finally, in terms of adherence to the recommendations made by these guidelines, protocols and algorithms, among the 81 participants who claimed to have guidelines or algorithms available, only $55.6 \%(\mathrm{n}=45)$ claimed to follow them "always or almost always," and only 9.9\% $(\mathrm{n}=8)$ stated that they "never or almost never" followed them.

\subsection{Subcutaneous hydration protocols (Table 3)}

Out of a total of 327 participants surveyed, $38.8 \%(n=127)$ claimed to have subcutaneous hydration protocols available at their service. With regard to who had compiled these protocols, $52.8 \%$ of those surveyed said that the creators were a mixed committee, made up in the majority of cases $(67.2 \%$; $n=45)$ by medical and nursing professionals, $35.4 \%$ by a team of nurses and $2.4 \%$ by a team of medical doctors.

Regarding the time when these protocols were created, the results show that they cover a period of 24 years, from 1990 to 2014, with $42.5 \% \quad(n=54)$ having been published in the previous decade and $31.5 \%(n=40)$ in the current decade. Furthermore, $78.7 \%(n=100)$ of participants, who said they had protocols, claimed to always or almost always follow their protocol, and only one participant indicated never or almost never doing so.

This article is protected by copyright. All rights reserved. 


\subsection{Usefulness as decision-making tools}

In those cases in which participants indicated that hydration algorithms or guidelines $(n=246)$ or subcutaneous hydration protocols $(\mathrm{n}=200)$ were not available, it was also asked whether they would be considered useful tools in an end-of-life context. In both cases, the majority considered that they would be useful: $80.9 \%(n=199)$ in the case of guidelines/algorithms and $78 \%(n=156)$ in the case of subcutaneous hydration protocols. There were four main themes described by the healthcare professionals (Table 4) with regard to the usefulness of these tools, of which three themes shared common views on guidelines, algorithms and protocols, and the fourth theme related only to the utility of guidelines. The first theme (T1): "Hydration guidelines, algorithms or protocols are considered necessary at this service for standardized and unified decision making," included two categories: "Standardizing the process based on scientific principles" and "Reducing variability in decision making processes." In this sense, participants made comments related to these tools as follows: "Guidelines, algorithms and protocols are the reference and baseline for assessment and personalized care."

The second theme arising from the responses (T2) was "Hydration guidelines and protocols are necessary as ongoing training and learning tools at services with healthcare professionals not specialized in palliative care" and included two semantic categories: "Necessary for nonspecialist healthcare professionals" and useful as "Ongoing training material for healthcare professionals." As an example, it was commented that they were useful for "Improving specific training and facilitating the standardization of care." The third common theme (T3) was "Guidelines and protocols are not necessary due to their inflexibility as a tool" and included two categories: "Inflexible tool which hinders personalization" and "Implicit procedure in the care process." As an example, one participant commented: "The decisions I make are clear enough for myself and obviously depend on each patient's individual situation."

This article is protected by copyright. All rights reserved. 
The fourth theme (T4), relating solely to guidelines and algorithms, was "Hydration guidelines and algorithms are necessary as informational support for families and reinforce healthcare professionals' decisions," with this being the sole semantic category. A supporting example among the healthcare professionals' claims was "Guidelines and algorithms are useful for us when it comes to our relation with patients' relatives. They need information and support to make decisions, and at the same time, we need a tool to base our recommendations on."

\section{Discussion}

The results reveal a limited availability of hydration guidelines and algorithms. Those available were created mainly by medical doctors and nurses between 2000 and 2009, with an adherence of slightly over $50 \%$ among those who claimed to have them available. The results regarding the use of subcutaneous hydration protocols showed that the protocols had a moderate degree of availability (approximately 40\%), had been compiled by committees comprising a mixture of medical doctors and nurses, had been compiled mostly during the decade from 2000 to 2009, and had a high degree of adherence.

Those healthcare professionals claiming not to have hydration guidelines, algorithms or protocols available nonetheless considered that they would be useful tools for standardizing and unifying criteria, as well as for ongoing training, and in the case of guidelines and algorithms, they would also consider them useful decision-making tools. Those who claimed that such tools were not useful considered them inflexible and/or implicit elements in healthcare processes (basic care as opposed to medical treatment).

The limited availability of guidelines and low adherence in the context of this study reveal, once again, the significant gap between research and practice (Cochrane et al., 2007). Studies exploring the implementation of and adherence to clinical guidelines in the healthcare field 
(Cabana et al., 1999; Davis \& Taylor-Vaisey, 1997; Fischer, Lange, Klose, Greiner, \& Kraemer, 2016) focus on identifying limiting factors or barriers to their availability. In this context, three main types of factors have been identified: personal factors (knowledge and attitude among professionals), factors relating to the characteristics of guidelines, and external factors relating mainly to organizational models (Fischer et al., 2016). These factors could be present and confluent in the context of the present study.

With regard to perceived usefulness, despite some respondents claiming not to have guidelines, algorithms or protocols available, the results show that they consider them to be useful tools. In consonance with other authors, these tools are seen to facilitate decisionmaking processes and diminish variability in clinical practice and ongoing training, with the main disadvantages being the lack of potential for personalizing care plans (Beghi et al., 1998; Fischer et al., 2016; Gundersen, 2000; Woolf, Grol, Hutchinson, Eccles, \& Grimshaw, 1999) and the perception of such interventions as a basic level of care given the symbolic value of hydration (Cabañero-Martínez et al., 2016; Gent et al., 2015).

From a clinical point of view, there is controversy about hydration at the end of life, and decisions should be made on an individual basis considering patient and family attitudes and values, which are based on the culture. In this sense, the participants in the study referred to the usefulness of the guides in making decisions shared with the family. We must bear in mind that according to the Sociological Research Center (2008), 89.7\% of the Spanish population considers the family very important, compared to $19.1 \%$ who consider religion very important and $17.3 \%$ who consider themselves to be practising Catholics (Sociological Research Center, 2015). This could explain why, although Spain is usually described as a country with a Catholic tradition, in our data, there are continuous references to the need to meet the demands of patients and their families and not to ethical or moral issues related to 
religious beliefs. In any case, our study does not examine the beliefs of families and patients, only those of professionals.

Considering this perspective, the results on the availability of and adherence to hydration guidelines and protocols could be explained, first, by the scarce and controversial evidence in favour of assisted hydration in patients with palliative needs and end-of-life situations (Forbat et al., 2017). In addition, they could be a consequence of the need, according to the participants, to personalize patient care plans, as suggested by previous studies (Arts et al., 2016), or they could be because this type of intervention is considered a basic level of care and not a medical treatment.

\subsection{Limitations}

To minimize the limitations derived from designing a questionnaire specific to the needs of this study, as well as from the data collection procedure applied, a study was performed prior to the final collection of data to examine the interpretability of the questionnaire. Likewise, a pilot study was carried out on the viability of the survey administration process. Furthermore, in regard to the questionnaire used, it must be mentioned that, as with all self-reporting methods, the reality of clinical practice may occasionally not be faithfully reflected (Mortel, 2008). Likewise, the methodology applied does not allow the identification of intra-service variability, which we attempted to reduce by interviewing the medical coordinators who are responsible for the implementation and follow-up of guidelines and protocols.

\section{Conclusion}

The present study demonstrates the limited availability of guidelines and protocols for deciding whether patients with palliative needs and in end-of-life situations should be hydrated and that only a moderate percentage of those surveyed have subcutaneous hydration 
protocols at their disposal. The services that do avail of these tools displayed moderate adherence to hydration guidelines and a high level of adherence to hypodermoclysis protocols. The remainder of the healthcare professionals surveyed, despite not having such tools available, considered them useful for standardizing care (reducing variability) and for ongoing training, as well as for decision-making processes in the case of hydration guidelines and algorithms. The main disadvantages in using such tools, as perceived by the participating professionals, were the lack of potential for personalizing care and the consideration of hydration as a basic form of care.

In line with our research, a future in-depth study on the barriers hindering the use of these tools in the context of palliative care in Spain would be of interest, as it could highlight their impact on clinical practice via longitudinal studies.

\subsection{Relevance to clinical practice}

Guidelines and protocols on hydration at the end of life are considered useful by health professionals, more as a solid reference and as support for individualized practice than as instruments for the standardization of care. From this perspective, the development and availability of such tools in palliative care services are recommended.

\section{Funding}

This study has been funded by a grant from the Institute of Health Carlos III (PI10/00847) of the Ministry of Economy and Competitiveness (Spain) and the European Regional Development Fund (FEDER).

\section{Conflict of interests}

The author declare that they have no conflict of interests

This article is protected by copyright. All rights reserved. 


\section{.REFERENCES}

Arts, D. L., Voncken, A. G., Medlock, S., Abu-Hanna, A., \& van Weert, H. C. P. M. (2016). Reasons for intentional guideline non-adherence: A systematic review. International Journal of Medical Informatics, 89, 55-62.

Audet, A. M., Greenfield, S., \& Field, M. (1990). Medical practice guidelines: current activities and future directions. Annals of Internal Medicine, 113(9), 709-14.

Bear, A. J., Bukowy, E. A., \& Patel, J. J. (2017). Artificial Hydration at the End of Life. Nutrition in Clinical Practice, 32(5), 628-632. https://doi.org/10.1177/0884533617724741

Beghi, E., Citterio, A., Cornelio, F., Filippini, G., Grilli, R., \& Liberati, A. (1998). Practice guidelines: a more rational approach to diagnosis and treatment and a more effective use of health care resources. Italian Journal of Neurological Sciences, 19(2), 120-3.

Broughton, R. (2001). What makes a good clinical guideline? Evidence Based Medicine, $1(11), 1-6$.

Cabana, M. D., Rand, C. S., Powe, N. R., Wu, A. W., Wilson, M. H., Abboud, P. A., \& Rubin, H. R. (1999). Why don't physicians follow clinical practice guidelines? A framework for improvement. JAMA, 282(15), 1458-65.

Cabañero-Martínez, M. J., Velasco-Álvarez, M. L., Ramos-Pichardo, J. D., Ruiz Miralles, M. L., Priego Valladares, M., \& Cabrero-García, J. (2016). Perceptions of health professionals on subcutaneous hydration in palliative care: A qualitative study. Palliative Medicine, 30(6), 549-557.

Cheung, C. R. L. H., \& Gray, J. A. M. (2013). Unwarranted variation in health care for children and young people. Archives of Disease in Childhood, 98(1), 60-5. https://doi.org/10.1136/archdischild-2012-302041

Cochrane, L. J., Olson, C. A., Murray, S., Dupuis, M., Tooman, T., \& Hayes, S. (2007). Gaps 
between knowing and doing: Understanding and assessing the barriers to optimal health care. Journal of Continuing Education in the Health Professions, 27(2), 94-102.

Considine, J., \& Hood, K. (2000). Emergency department management of hip fractures: Development of an evidence-based clinical guideline by literature review and consensus. Emergency Medicine Australasia, 12(4), 329-336.

Cook, D. A., Pencille, L. J., Dupras, D. M., Linderbaum, J. A., Pankratz, V. S., \& Wilkinson, J. M. (2018). Practice variation and practice guidelines: Attitudes of generalist and specialist physicians, nurse practitioners, and physician assistants. PloS One, 13(1), e0191943.

Corallo, A. N., Croxford, R., Goodman, D. C., Bryan, E. L., Srivastava, D., \& Stukel, T. A. (2014). A systematic review of medical practice variation in OECD countries. Health Policy, 114(1), 5-14.

Davis, D. A., \& Taylor-Vaisey, A. (1997). Translating guidelines into practice. A systematic review of theoretic concepts, practical experience and research evidence in the adoption of clinical practice guidelines. CMAJ : Canadian Medical Association Journal = Journal de l'Association Medicale Canadienne, 157(4), 408-16.

Druml, C., Ballmer, P. E., Druml, W., Oehmichen, F., Shenkin, A., Singer, P., ... Bischoff, S. C. (2016). ESPEN guideline on ethical aspects of artificial nutrition and hydration.

Fischer, F., Lange, K., Klose, K., Greiner, W., \& Kraemer, A. (2016). Barriers and Strategies in Guideline Implementation-A Scoping Review. Healthcare, 4(3), 36.

Forbat, L., Kunicki, N., Chapman, M., \& Lovell, C. (2017). How and why are subcutaneous fluids administered in an advanced illness population: a systematic review. Journal of Clinical Nursing, 26(9-10), 1204-1216.

Gent, M. J., Fradsham, S., Whyte, G. M., \& Mayland, C. R. (2015). What influences attitudes towards clinically assisted hydration in the care of dying patients? A review of the

This article is protected by copyright. All rights reserved. 
literature. BMJ Supportive \& Palliative Care, 5(3), 223-231.

Good, P., Richard, R., Syrmis, W., Jenkins-Marsh, S., \& Stephens, J. (2014). Medically assisted hydration for adult palliative care patients. Cochrane Database of Systematic Reviews, (4), CD006273.

Gouvêa, M., Novaes, C. de O., Pereira, D. M. T., \& Iglesias, A. C. (2015). Adherence to guidelines for surgical antibiotic prophylaxis: a review. The Brazilian Journal of Infectious Diseases, 19(5), 517-524.

Guba, E. G., \& Lincoln Y.S. (1994). Competing paradigms in qualitative research. In N. K. Denzin \& Y. S. Lincoln (Eds.), Handbook of qualitative research (pp. 105-117). Thousand Oaks, CA, US: Sage Publications, Inc.

Gundersen, L. (2000). The Effect of Clinical Practice Guidelines on Variations in Care. Annals of Internal Medicine, 133(4), 317.

Gupta, K. J., \& Cook, T. M. (2013). Accidental hypoglycaemia caused by an arterial flush drug error: a case report and contributory causes analysis. Anaesthesia, 68(11), 11791187. https://doi.org/10.1111/anae.12388

Hewitt-Taylor, J. (2004). Clinical guidelines and care protocols. Intensive \& Critical Care Nursing, 20(1), 45-52.

Higgins, I., van der Riet, P., Sneesby, L., \& Good, P. (2014). Nutrition and hydration in dying patients: the perceptions of acute care nurses. Journal of Clinical Nursing, 23(17-18), 2609-2617.

Institute of Medicine (US) Committee to Advise the Public Health Service on Clinical Practice Guidelines, Field, M., \& Lohr, K. (1990). Clinical Practice Guidelines. Washington, D.C.: National Academies Press.

Keffer, J. H. (2001). Guidelines and algorithms: perceptions of why and when they are successful and how to improve them. Clinical Chemistry, 47(8), 1563-72.

This article is protected by copyright. All rights reserved. 
Malhotra, C., Chan, N., Zhou, J., Dalager, H. B., \& Finkelstein, E. (2015). Variation in physician recommendations, knowledge and perceived roles regarding provision of endof-life care. BMC Palliative Care, 14(1), 52. https://doi.org/10.1186/s12904-015-0050-y

Mercuri, M., \& Gafni, A. (2011). Medical practice variations: what the literature tells us (or does not) about what are warranted and unwarranted variations. Journal of Evaluation in Clinical Practice, 17(4), 671-677.

Mortel, T. van de. (2008). Faking it: social desirability response bias in self-report research. Australian Journal of Advanced Nursing, 25(4), 40-48.

Nakajima, N., Satake, N., \& Nakaho, T. (2014). Indications and practice of artificial hydration for terminally ill cancer patients. Current Opinion in Supportive and Palliative Care, 8(4), 358-363.

National Institute for Health and Care Excellence. (2015). Care of dying adults in the last days of life | Guidance and guidelines | NICE. NICE Guidelines.

Nouhi, M., Hadian, M., \& Olyaeemanesh, A. (2018). The clinical and economic consequences of practice style variations in common surgical interventions. Medicine, 97(42), e12439. https://doi.org/10.1097/MD.0000000000012439

Papanikitas, A., \& Lunan, C. (2018). Inside general practice ethics: guidelines “and” “of” or “for” good clinical practice. London Journal of Primary Care, 10(2), 34-38. https://doi.org/10.1080/17571472.2018.1437028

Pellet, A. C., Erten, M. Z., \& James, T. A. (2016). Value analysis of postoperative staging imaging for asymptomatic, early-stage breast cancer: implications of clinical variation on utility and cost. The American Journal of Surgery, 211(6), 1084-1088. https://doi.org/10.1016/j.amjsurg.2015.08.022

Prior, M., Guerin, M., \& Grimmer-Somers, K. (2008). The effectiveness of clinical guideline implementation strategies - a synthesis of systematic review findings. Journal of

This article is protected by copyright. All rights reserved. 
Evaluation in Clinical Practice, 14(5), 888-897.

Río, M. I., Shand, B., Bonati, P., Palma, A., Maldonado, A., Taboada, P., \& Nervi, F. (2012). Hydration and nutrition at the end of life: a systematic review of emotional impact, perceptions, and decision-making among patients, family, and health care staff. PsychoOncology, 21(9), 913-921.

Schellart, A. J., Zwerver, F., Anema, J. R., \& van der Beek, A. J. (2013). Relationships between the intention to use guidelines, behaviour of insurance physicians and their determinants. BMC Health Services Research, 13(1), 400.

Sociological Research Center. (2008). Religiosity. Madrid (Spain). Retrieved from http://www.cis.es/cis/export/sites/default/-

Archivos/Marginales/2740_2759/2759/es2759.pdf

Sociological Research Center. (2015). Spanish General Social Survey. Madrid (Spain).

Retrieved from http://www.cis.es/cis/export/sites/default/Archivos/Marginales/3120_3139/3123/es3123mar.pdf

Tomasone, J. R., Chaudhary, R., \& Brouwers, M. C. (2015). Effectiveness of guideline dissemination and implementation strategies on health care professionals' behaviour and patient outcomes in the cancer care context: a systematic review protocol. Systematic Reviews, 4, 113.

Torres-Vigil, I., Mendoza, T. R., Alonso-Babarro, A., De Lima, L., Cárdenas-Turanzas, M., Hernandez, M., ... Bruera, E. (2012). Practice Patterns and Perceptions About Parenteral Hydration in the Last Weeks of Life: A Survey of Palliative Care Physicians in Latin America. Journal of Pain and Symptom Management, 43(1), 47-58. https://doi.org/10.1016/j.jpainsymman.2011.03.016

Van Brabandt, H., Camberlin, C., Vrijens, F., Parmentier, Y., Ramaekers, D., \& Bonneux, L. (2006). More is not better in the early care of acute myocardial infarction: a prospective 
cohort analysis on administrative databases. European Heart Journal, 27(22), 26492654. https://doi.org/10.1093/eurheartj/ehl161

Vandenbroucke, J. P., von Elm, E., Altman, D. G., Gøtzsche, P. C., Mulrow, C. D., Pocock, S. J., ... STROBE Initiative. (2007). Strengthening the Reporting of Observational Studies in Epidemiology (STROBE): explanation and elaboration. Epidemiology (Cambridge, Mass.), 18(6), 805-35. https://doi.org/10.1097/EDE.0b013e3181577511

Woolf, S. H., Grol, R., Hutchinson, A., Eccles, M., \& Grimshaw, J. (1999). Clinical guidelines: potential benefits, limitations, and harms of clinical guidelines. $B M J$ (Clinical Research Ed.), 318(7182), 527-30.

This article is protected by copyright. All rights reserved. 
Table 1. Sample Characteristics $(n=327)$

\begin{tabular}{|c|c|c|}
\hline & $\%$ & $\mathbf{n}$ \\
\hline \multicolumn{3}{|l|}{ Autonomous Community* $(n=327)$} \\
\hline Cataluña & 32.7 & 107 \\
\hline Valencia & 10.1 & 33 \\
\hline Andalucía & 10.1 & 33 \\
\hline Madrid & 9.8 & 32 \\
\hline Galicia & 6.4 & 21 \\
\hline Castilla y León & 4.9 & 16 \\
\hline País Vasco & 4.0 & 13 \\
\hline Murcia & 4.0 & 13 \\
\hline Castilla la Mancha & 3.7 & 12 \\
\hline Extremadura & 3.1 & 10 \\
\hline Asturias & 2.1 & 7 \\
\hline Canarias & 2.1 & 7 \\
\hline Baleares & 1.8 & 6 \\
\hline Cantabria & 1.5 & 5 \\
\hline Aragón & 1.2 & 4 \\
\hline La Rioja & 0.9 & 3 \\
\hline Navarra & 0.9 & 3 \\
\hline Ceuta y Melilla & 0.6 & 2 \\
\hline \multicolumn{3}{|l|}{ Context (n=327) } \\
\hline Hospital only & 32.7 & 107 \\
\hline Home only & 44.7 & 146 \\
\hline Mixed & 22.6 & 74 \\
\hline \multicolumn{3}{|l|}{ Medical History $(\mathrm{n}=327)$} \\
\hline Oncological & 8.6 & 28 \\
\hline Non-oncological & 0.9 & 3 \\
\hline Both & 90.5 & 296 \\
\hline \multicolumn{3}{|l|}{ Interviewee (behalf of the team) $(n=327)$} \\
\hline \multicolumn{3}{|l|}{ Medical coordinator } \\
\hline Nursing coordinator & 87.8 & 287 \\
\hline Other team doctor & 2.1 & 7 \\
\hline \multirow[t]{3}{*}{ Other team nurse } & 8.0 & 26 \\
\hline & 2.1 & 7 \\
\hline & Mean & SD \\
\hline Patients per day $(n=326)$ & 24.1 & $(25.9)$ \\
\hline Palliative patients per day $(n=326)$ & 17.1 & $(17.7)$ \\
\hline Doctors per service $(n=325)$ & 2.6 & $(3.0)$ \\
\hline Nurses per service $(n=326)$ & 4.7 & $(5.5)$ \\
\hline
\end{tabular}

*Autonomous Community: In Spain, a territorial entity which, within the constitutional order of the State, is endowed with legislative power and executive powers, as well as the power to govern itself through its own representatives (Royal Spanish Language Academy, 2019).

This article is protected by copyright. All rights reserved. 
Table 2. Existence of decision-making algorithms/guidelines regarding hydration.

\begin{tabular}{|c|c|c|c|}
\hline & $\%$ & $\mathbf{n}$ & $95 \% \mathrm{CI}$ \\
\hline \multicolumn{4}{|c|}{$\begin{array}{l}\text { Guidelines/Algorithms regarding hydration available } \\
(\mathrm{n}=327)\end{array}$} \\
\hline Yes & 24.8 & 81 & 27.36-39.02 \\
\hline No & 75.2 & 246 & $70.28-79.60$ \\
\hline \multicolumn{4}{|l|}{ Author of guideline/algorithm $(n=81)$} \\
\hline Nursing team & 2.5 & 2 & $0.68-8.56$ \\
\hline Medical team & 9.9 & 8 & $5.09-18.30$ \\
\hline Mixed committee & 75.3 & 61 & $64.92-83.41$ \\
\hline Other (already compiled) & 8.6 & 7 & $4.25-16.78$ \\
\hline Unknown & 3.7 & 3 & $1.27-10.33$ \\
\hline \multicolumn{4}{|l|}{ Mixed committee $(n=61)$} \\
\hline Doctors and nurses & 63.9 & 39 & $69.89-79.36$ \\
\hline Doctors, nurses and other professionals & 11.5 & 7 & $67.26-77.03$ \\
\hline All team members & 8.3 & 5 & $9.62-16.97$ \\
\hline Different medical specialists & 1.6 & 1 & $8.53-15.58$ \\
\hline Unknown & 14.7 & 9 & $3.35-8.37$ \\
\hline \multicolumn{4}{|l|}{ Date created $(n=81)$} \\
\hline 1990-1999 & 8.6 & 7 & $4.25-16.78$ \\
\hline 2000-2009 & 43.2 & 35 & $32.97-54.06$ \\
\hline 2010-2014 & 32.1 & 26 & $22.94-42.88$ \\
\hline Unknown & 16.1 & 13 & $9.63-25.55$ \\
\hline \multicolumn{4}{|c|}{ Degree of adherence to guideline/algorithm $(n=81)$} \\
\hline Always or almost always & 55.6 & 45 & $44.73-65.88$ \\
\hline Often & 30.8 & 25 & $21.86-41.60$ \\
\hline Sometimes & 3.7 & 3 & $1.27-10.33$ \\
\hline Never or almost never & 9.9 & 8 & $5.09-18.30$ \\
\hline
\end{tabular}

This article is protected by copyright. All rights reserved. 


\begin{tabular}{l|l|l|l}
\hline & \% & $\mathbf{n}$ & $\mathbf{9 5 \%}$ CI \\
\hline Subcutaneous hydration protocol available $(\mathbf{n = 3 2 7})$ & & & \\
Yes & 38.8 & 127 & $33.71-44.22$ \\
No & 61.2 & 200 & $55.78-66.29$
\end{tabular}

Author of SC hydration protocol $(n=127)$

Nursing team

Medical team

Mixed committee

Other (already compiled)

Unknown

\section{Mixed committee $(n=67)$}

Doctors and nurses

Doctors, nurses and other professionals

All team members

Unknown

Date created $(n=127)$

1990-1999

2000-2009

2010-2014

Unknown

Degree of adherence to SC hydration protocol $(n=127)$

Always or almost always

Often

Sometimes

Never or almost never

$\begin{array}{lll}35.4 & 45 & 27.65-44.07 \\ 2.4 & 3 & 0.81-6.72 \\ 52.8 & 67 & 44.12-61.23 \\ 6.3 & 8 & 3.23-11.94 \\ 1.2 & 4 & 1.23-7.82\end{array}$

55.26-77.21

4.17-18.19

$11.9 \quad 8$

$10.44-28.58$

11.98

$10.44-28.58$

$\begin{array}{lll}10.2 & 13 & 6.08-16.73 \\ 42.5 & 54 & 34.27-51.21 \\ 31.5 & 40 & 24.06-40.02 \\ 15.8 & 20 & 10.43-23.08\end{array}$

$\begin{array}{lll}78.7 & 100 & 70.84-84.96 \\ 16.5 & 21 & 11.08-23.96 \\ 4.0 & 5 & 1.69-8.89 \\ 0.8 & 1 & 0.14-4.33\end{array}$

This article is protected by copyright. All rights reserved. 
Table 4. Qualitative analysis: themes and categories.

\begin{tabular}{|c|c|c|}
\hline THEMES & CATEGORIES & NARRATIVE \\
\hline $\begin{array}{l}\text { T1: Hydration guidelines, } \\
\text { algorithms or protocols are } \\
\text { considered necessary by the } \\
\text { service for standardized and } \\
\text { unified decision making. }\end{array}$ & $\begin{array}{l}\text { 1. Standardizing the process } \\
\text { based on scientific principles. } \\
2 . \quad \text { Reducing variability in } \\
\text { decision-making processes. }\end{array}$ & $\begin{array}{l}\text { "Endorsed clinical judgement, } \\
\text { criteria" } \\
\text { "To make consensus-based } \\
\text { team decisions" } \\
\text { "Standardizing anything } \\
\text { facilitates practice" } \\
\text { "Guidelines, algorithms and } \\
\text { protocols are the reference and } \\
\text { baseline for assessment and } \\
\text { personalized care" }\end{array}$ \\
\hline $\begin{array}{l}\text { T2: Hydration guidelines, } \\
\text { algorithms and protocols are } \\
\text { necessary as ongoing training } \\
\text { and learning tools at services } \\
\text { with healthcare professionals } \\
\text { not specialized in palliative } \\
\text { care. }\end{array}$ & $\begin{array}{l}\text { 1. Necessary for non- } \\
\text { specialist healthcare professionals. } \\
2 . \quad \text { Ongoing training material } \\
\text { for healthcare professionals. }\end{array}$ & $\begin{array}{l}\text { "Agreement among } \\
\text { professionals through } \\
\text { communication between non- } \\
\text { palliative specialists and } \\
\text { palliative specialist doctors" } \\
\text { "Improving specific training } \\
\text { and facilitate the } \\
\text { standardization of care" }\end{array}$ \\
\hline $\begin{array}{l}\text { T3: Guidelines, algorithms } \\
\text { and protocols are not } \\
\text { necessary due to their } \\
\text { inflexibility as a tool. }\end{array}$ & $\begin{array}{l}\text { 1. Inflexible tool which } \\
\text { hinders personalization. } \\
2 . \quad \text { Implicit procedure in the } \\
\text { care process. }\end{array}$ & $\begin{array}{l}\text { "The decisions I make are clear } \\
\text { enough for myself and } \\
\text { obviously depend on each } \\
\text { patient's individual situation" } \\
\text { "Personalized medicine, not for } \\
\text { protocol's sake, personalizing } \\
\text { care is a must" } \\
\text { "The information already } \\
\text { exists, not on its own but as a } \\
\text { part of end-of-life care" }\end{array}$ \\
\hline $\begin{array}{l}\text { T4: Hydration guidelines and } \\
\text { algorithms are necessary as } \\
\text { informational support for } \\
\text { families and reinforce } \\
\text { healthcare professionals' } \\
\text { decisions. }\end{array}$ & $\begin{array}{l}\text { 1. Facilitating decision } \\
\text { making together with families. }\end{array}$ & $\begin{array}{l}\text { "Guidelines and algorithms are } \\
\text { useful for us when it comes to } \\
\text { our relation with patients" } \\
\text { relatives. They need } \\
\text { information and support to } \\
\text { make decisions and at the same } \\
\text { time we need a tool to base our } \\
\text { recommendations on" } \\
\text { "A means of support for } \\
\text { negotiating with families" }\end{array}$ \\
\hline
\end{tabular}

This article is protected by copyright. All rights reserved. 